\title{
The Influence of Maintenance Energy and Growth Rate on the Metabolic Activity, Morphology and Conidiation of Penicillium chrysogenum
}

\author{
By R. C. RIGHELATO, A. P. J. TRINCI, S. J. PIRT \\ Department of Microbiology, Queen Elizabeth College, \\ University of London, $W .8$
}

\author{
AND A. PEAT \\ Department of Botany, University of Durham
}

(Accepted for publication I7 August 1967)

\begin{abstract}
SUMMARY
The rates of utilization of energy-yielding substrates (glucose and oxygen) by Penicillium chrysogenum in glucose-limited chemostat cultures were resolved into requirements or 'rations' for growth and maintenance. The maintenance ration of glucose was almost all oxidized to carbon dioxide. Over the growth rate range $0.023-0.075 \mathrm{hr}^{-1}$ only vegetative growth occurred; although the filamentous growth form predominated, the occurrence of pellets and swollen organisms increased with growth rate. At growth rates of $0.014 \mathrm{hr}^{-1}$ and below, conidiation occurred and was maximal at a specific growth rate of $0.009 \mathrm{hr}^{-1}$ (average doubling time $78 \mathrm{hr}$ ). After growth in chemostat culture the organism could be maintained in a non-growing state by supplying only the maintenance ration of glucose $(0.022 \mathrm{~g}$. glucose $/ \mathrm{g}$. mycelial dry wt/hr). When growth in the chemostat was suddenly stopped by stopping the glucose feed, the mould autolyzed; autolysis was prevented by supplying the maintenance ration of glucose. When the glucose feed rate in chemostat cultures was decreased to the maintenance ration, mycelial differentiation occurred. Differentiation involved increased hyphal vacuolation, a decreased degree of oxidation of glucose, breakdown and resynthesis of nucleic acids and conidiation. The rates at which these changes occurred were inversely related to the growth rate prior to stopping growth. For maximum conidia formation there was an optimal glucose feed rate about $0.038 \mathrm{~g}$. glucose $/ \mathrm{g}$. mycelial dry $\mathrm{wt} / \mathrm{hr}$, that is $\mathrm{I} \cdot 7 \times$ maintenance ration. The maintenance ration of glucose was shown to play a role in preventing autolysis and facilitating conidiation. Electron microscope studies showed that there was no change in the observed ultrastructure of cells (except degree of vacuolation) with change in specific growth rate from near the maximum to zero. The septa of the hyphae were found to be plugged.
\end{abstract}

\section{INTRODUCTION}

The relatively slow growth rates and inconvenient growth form of filamentous fungi in submerged culture has led to their growth kinetics being neglected by comparison with unicellular organisms. Smith (I924) showed the growth of individual hyphal systems to be exponential, but it has only recently been established that the growth of fungi in submerged cultures can follow the exponential law (reviewed by Pirt, 1966). 
It has also been shown that the chemostat continuous culture principle can be applied to the growth of a filamentous mould (Pirt \& Callow, 1960). In the present work the chemostat method has been applied to determine the influence of growth rate on the carbon and energy requirement of Penicillium chrysogenum. At the same time the influence of growth rate on the morphology of the mould was investigated; there appears to be no previous study of cell morphology in relation to growth rate.

Maintenance energy. The concept of maintenance energy in bacterial cultures was reviewed by Pirt (1965). In general, metabolic activities may be resolved into growthrate dependent and growth-rate independent components. If $q=$ metabolic quotient (g. material metabolized/g. dry wt organism/hr), we can write

$$
q=\alpha \mu+\beta,
$$

where $\beta=$ growth rate independent component and $\alpha \mu=$ growth rate dependent component ( $\mu=$ specific growth rate, $\alpha$ is a constant).

For substrate $(s)$ utilization in small time interval $d t$ we can write

$$
-d s=\frac{d x}{Y_{g}}+m x d t
$$

where $Y_{g}=$ true growth yield, $x=$ organism concentration and $m=$ maintenance coefficient.

Hence

Substitute in (2)

$$
\frac{-d s}{d t}=\frac{\mathrm{I}}{Y_{g}} \frac{d x}{d t}+m x
$$

and we have

$$
\frac{-d s}{d t}=q x, \text { and } \frac{d x}{d t}=\mu x
$$

Relation (4) is a special case of (I).

$$
q=\frac{\mu}{Y_{g}}+m
$$

In the chemostat we can vary $\mu$, measure $q$ and thus estimate $m$ and $Y_{g}$ by means of equation (4). So-called maintenance functions probably include turnover of macromolecules, osmotic regulation, cellular organization and special activities such as motility or production of secondary metabolites such as penicillin. In the present study we determined the specific rates of metabolism of the main substrates and products of carbon and energy metabolism (glucose, oxygen, mycelium, carbon dioxide) of a Penicillium chrysogenum strain at different growth rates in glucose-limited chemostats.

Morphology. A variety of environmental factors have been shown to affect gross morphology, fine structure and morphogenesis in fungi. Hydrogen ion concentration is an important factor in determining the predominance of the filamentous or pellet growth form in Penicillium chrysogenum (Pirt \& Callow, 1959), whilst the atmosphere of incubation has been shown to play a role in the dimorphism of Mucor rouxii (Bartnicki-Garcia \& Nickerson, 1962). Nutrition is another factor of prime importance. For instance, nitrogen exhaustion caused conidiation in Penicillium griseofulvum and related species (Morton, 196I) and Hawker (1939) has shown the importance of carbohydrate availability to fungal morphogenesis. The present work with $P$. chrysogenum adds growth rate to the list of parameters which can affect morphology. In morphological studies, therefore, careful consideration must be given to the conditions of growth of the organism. The practise of using fungi grown on defined media in shake flasks for morphological studies gives reproducible results, but their interpretation 
is complicated by the ill-defined and transient nature of the environmental conditions in the sequential growth phases. The use of stirred culture vessels improves the homogeneity of cultures and allows precise control of factors such as $\mathrm{pH}$ value, aeration and nutrient supply. The chemostat type of continuous culture in addition enables control of growth rate. We are aware of only one study of mould morphology in which a chemostat was used (Pirt \& Callow, 1959).

\section{METHODS}

Growth rate. Specific growth rate $(\mu)$ is used to refer to the growth rate per unit mass of organism. If $x$ is the mass of organism and $t$ is time (hr) then

$$
\mu=(\mathrm{I} / x)(d x / d t)\left(\mathrm{hr}^{-1}\right) \text {. }
$$

The specific growth rate is related to the doubling time $\left(t_{d}\right)$ by the expression,

$$
\mu=\left(\log _{e} 2\right) / t_{d} \text {. }
$$

Apparatus. Two-litre cultures were made in a vessel adapted for continuous cultivation of filamentous micro-organisms (Righelato \& Pirt, 1967).

Cultural conditions. Medium (g./1.): glucose, $2 \cdot 3 \times$ dry wt organism required; $\mathrm{K}_{2} \mathrm{HPO}_{4}, 6.00 ; \mathrm{NaH}_{2} \mathrm{PO}_{4}, \mathrm{I} \cdot 86 ; \mathrm{MgSO}_{4} \cdot 7 \mathrm{H}_{2} \mathrm{O}, 0.25 ; \mathrm{CaCl}_{2}, 0.05 ; \mathrm{ZnSO}_{4} \cdot 7 \mathrm{H}_{2} \mathrm{O}$, $0.02 ; \mathrm{MnSO}_{4} .4 \mathrm{H}_{2} \mathrm{O}, 0.02 ; \mathrm{CuSO}_{4} .5 \mathrm{H}_{2} \mathrm{O}, 0.005 ; \mathrm{FeSO}_{4} .7 \mathrm{H}_{2} \mathrm{O}, 0.10 ; \mathrm{Na}_{2} \mathrm{SO}_{4}, \mathrm{I} \cdot 00$; disodium ethylene-diaminotetracetic acid (EDTA), 0.60; $\left(\mathrm{NH}_{4}\right)_{2} \mathrm{SO}_{4}, 4 \cdot 72$; phenylacetic acid (neutralized with $\mathrm{NaOH}$ ) I $\bullet \circ$. Glucose and phenylacetate, phosphates and salts solution were each autoclaved separately. Glucose was the growth-limiting substrate in this medium up to a mycelium dry wt of at least $20 \mathrm{~g} . / 1$. The dry wt of organism did not exceed $14 \mathrm{~g}$./1. medium in the work described here. The residual glucose concentration was always $<0 . \mathrm{I}$ g./l. Glucose and phenylacetate were fed separately from the rest of the medium; in some batch cultures the specific glucose supply rate (g. glucose/g. mycelium dry wt/hr) was kept constant by frequent manual adjustment of the metering pumps. The $\mathrm{pH}$ value was controlled at $7 \cdot 0 \pm 0 \cdot \mathrm{I}$ by automatic addition of $2 \mathrm{~N}-\mathrm{NH}_{4} \mathrm{OH}$ or $2 \mathrm{~N}-\mathrm{H}_{2} \mathrm{SO}_{4}$ and temperature was controlled at $25^{\circ}$. Foaming was controlled by automatic addition of polypropyleneglycol ( $\mathrm{P} 2000$ Dow Chemical Co. (U.K.) Ltd., I05 Wigmore St, London, W. I) at 4-hr intervals, to give a concentration of about $0.1 \mathrm{ml}$./1. culture. The air flow through the culture was adjusted to give $\mathrm{I}$ to $3 \%(\mathrm{v} / \mathrm{v})$ carbon dioxide in the effluent air. The dissolved oxygen concentration as recorded by an oxygen electrode was $70-100 \%$ of the saturation value.

Organism. Penicillium chrysogenum wIS 54-1255 was used; it was maintained on slopes of the sporulation medium of Moyer \& Coghill (1946). Spore inocula were produced on bran cultures (Whiffen \& Savage, 1947) and inoculated into the germination medium of Jarvis \& Johnson (1947). After germination the inoculum was transferred to the fermentor.

Analytical methods. The organism concentration was measured as equiv. mycelium dry wt after filtration of $10 \mathrm{ml}$. culture, twice washing with $\mathrm{I} 5 \mathrm{ml}$. distilled water, and drying at $105^{-1} 10^{\circ}$ to constant weight. Glucose concentrations were measured by a glucose oxidase method (Blood sugar kit, Boehringer Corporation (London) Ltd., Bilton House, 54/58 Uxbridge Road, Ealing, London, W. 5). Ammonia was estimated by the microdiffusion method of Conway (I957). Mycelial nitrogen was converted to 
ammonia by Kjeldahl digestion and estimated by Conway's method. Cell carbon and hydrogen analyses were kindly done by the analytical department of the Chemical Defence Experimental Establishment, Porton, Wiltshire. Total mycelial carbohydrate was estimated by an anthrone method (Trevelyan \& Harrison, 1952) and mycelial protein by a biuret method (Stickland, 195I). Nucleic acids were extracted with $0.5 \mathrm{~N}-$ $\mathrm{HClO}_{4}$ at $70^{\circ}$ after removal of the ice-cold $0.2 \mathrm{~N}-\mathrm{HClO}_{4}$ soluble fraction. Ribonucleic acid was calculated from the ribose content of the extract estimated by the orcinol method (Umbreit, Burris \& Stauffer, 1947) and deoxyribonucleic acid from the deoxyribose estimated by the diphenylamine method (Burton, 1956). Penicillin was estimated by a cup method with Bacillus subtilis as the assay organism.

The oxygen content of the effluent air was measured by a Paramagnetic Oxygen Analyser, Mark II (Servomex Controls Ltd., Crowborough, Sussex). Carbon dioxide output was measured by washing the effluent air with $\mathrm{KOH}$ in an Orsat apparatus. Acid production was measured by the accumulation of ammonia, the $\mathrm{pH}$ control agent, in the culture filtrate.

Light and electron microscopy. The culture samples for light microscopy were fixed in equal volumes of formal-acet-alcohol (formalin ( $\mathrm{HCHO} 40 \%$, w/v) $13 \mathrm{ml}$. + glacial acetic acid, $5 \mathrm{ml} .+50 \%(\mathrm{v} / \mathrm{v})$ ethanol in water, $200 \mathrm{ml}$.). Conidia were counted by using the fixed material in a Helber chamber. The hyphae were stained with trypan blue in lactophenol (lactophenol, $100 \mathrm{ml}$. and trypan blue, $0.25 \mathrm{~g}$.). The photographs were taken with a Zeiss photomicroscope, measurements of hyphal dimensions were taken from the photographs.

For observation with the electron microscope culture samples were fixed in $2 \%$ $(\mathrm{w} / \mathrm{v}) \mathrm{KMnO}_{4}$ in veronal acetate buffer $\left(\mathrm{pH} \mathrm{6.5)}\right.$ for $\mathrm{I} \mathrm{hr}$ at about $\mathrm{I} 8^{\circ}$. The hyphae were dehydrated in ethanol-water mixtures and embedded in araldite. Sections were cut with an LKB ultramicrotome with glass knives and viewed in an AEI EM6B microscope.

\section{RESULTS}

\section{The influence of growth rate on metabolic quotients}

The specific rates of utilization of oxygen and glucose by Penicillium chrysogenum WIS 54-I255 in steady state glucose-limited chemostat cultures were measured over the growth rate range $0.014-0.075 \mathrm{hr}^{-1}$ (maximum specific growth rate $=0.09 \mathrm{hr}^{-1}$ ). Straight line relationships of the type described by equation (4) were obtained (Fig. I). These, together with the constant respiratory quotient $\left(\mathrm{CO}_{2} / \mathrm{O}_{2}=0.97 \pm 0.03\right)$, indicate that the glucose metabolism remained qualitatively the same over the range of growth rates investigated. Similar linear relationships between $Q_{\mathrm{o}_{\mathbf{2}}}$ and dilution rates were described by Herbert (1958) for glycerol-limited growth of Aerobacter aerogenes and by Tempest \& Herbert (1965) for Torula utilis with growth limited either by carbon or by nitrogen source.

The intercepts on the ordinates of Fig. I are the maintenance coefficients for glucose and oxygen, $0.12 \mathrm{~m}$-moles $(0.022 \mathrm{~g}$.) glucose $/ \mathrm{g}$. mycelium dry $\mathrm{wt} / \mathrm{hr}$ and $0.74 \mathrm{~m}$-moles $\mathrm{O}_{2} / \mathrm{g}$. dry wt/hr. The only previous report of a maintenance coefficient for a filamentous mould is by Terroine \& Wurmser (I922) who calculated a value of o. I I g. glucose/g. dry wt/hr. However, their experimental method depended on decreasing the growth rate by lowering the $\mathrm{pH}$ value to a growth-inhibitory value. Qualitative differences in metabolism may have occurred at the different $\mathrm{pH}$ values, 
altering both growth yield and maintenance coefficients and thus invalidating their calculations. The value for the maintenance coefficient found here for Penicillium chrysogenum growing aerobically on glucose at $25^{\circ}$ is considerably lower than those found for bacteria. Pirt (1965) observed a maintenance coefficient of $0.094 \mathrm{~g}$. glucose/ g. dry wt/hr with Aerobacter cloacae under aerobic conditions in a glucose-limited chemostat at $37^{\circ}$. The higher coefficient of $A$. cloacae may have resulted from the higher growth temperature.

Elementary analysis of the dried Penicillium mycelium showed that carbon and hydrogen contents were unaffected by the growth rate (Fig. 2) but the nitrogen con-

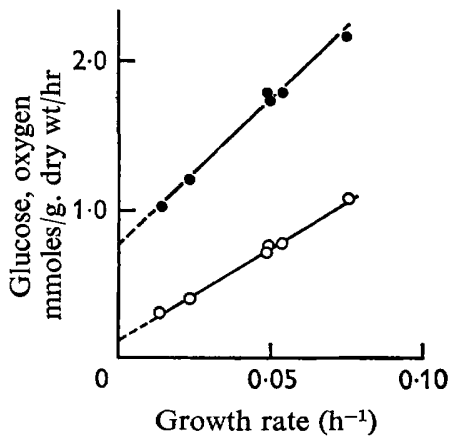

Fig. I

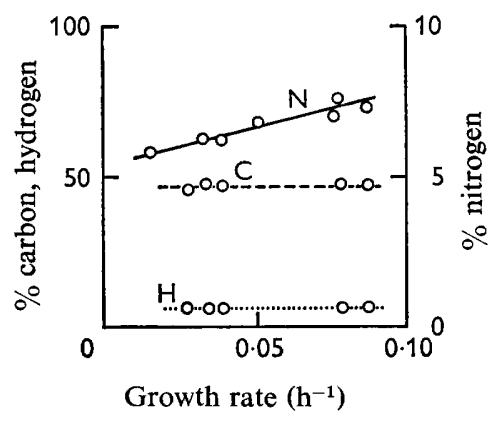

Fig. 2

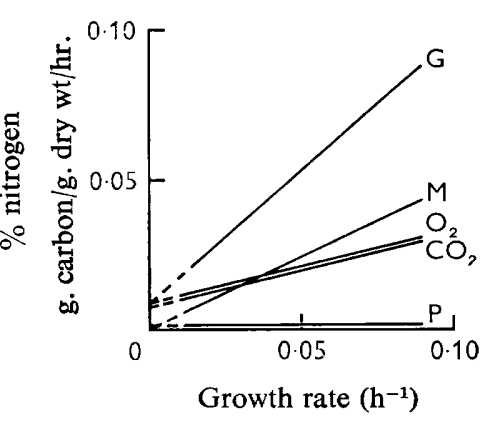

Fig. 3

Fig. I. The relationship between specific growth rate and the specific utilization rates of glucose (O), and oxygen (๑) of Penicillium chrysogenum wis 54-1255 in steady state glucose-limited chemostat culture. Each point represents the mean of one steady state. $\mathrm{I} /$ slope of glucose line $=$ growth yield $=0.08 \mathrm{I} \mathrm{g}$. dry $\mathrm{wt} / \mathrm{m}-\mathrm{mole}$ glucose consumed. Intercept of glucose line on ordinate $=$ maintenance coefficient $=0.12 \mathrm{~m}$-moles glucose $/$ g. dry wt $/ \mathrm{hr}$. I $/$ slope of oxygen line $=$ growth yield $=0.050 \mathrm{~g}$. dry $\mathrm{wt} / \mathrm{m}-\mathrm{mole} \mathrm{O}_{2}$. Intercept of oxygen line on ordinate $=$ maintenance coefficient $=0.74 \mathrm{~m}-\mathrm{moles} \mathrm{O}_{2} / \mathrm{g}$. dry wt $/ \mathrm{hr}$.

Fig. 2. The relationship between specific growth rate and carbon, hydrogen and nitrogen content of Pencillium chrysogenum wIS 54-1255 in steady-state glucose-limited chemostat cultures.

Fig. 3. The recovery of glucose, carbon and oxygen as carbon dioxide, mycelial carbon and penicillin carbon in glucose-limited chemostat cultures of Penicillium chrysogenum wIS 54-I255 at growth rates from 0.014 to $0.075 \mathrm{hr}^{-1}$. G, glucose carbon; M, mycelial carbon; $\mathrm{CO}_{2}, \mathrm{CO}_{2}$-carbon; $\mathrm{O}_{2}, \mathrm{O}_{2}$ utilized as equivalent $\mathrm{CO}_{2} ; \mathrm{P}$, penicillin-carbon.

tent increased with the growth rate. The increase in nitrogen content probably reflected an increase in ribonucleic acid (RNA) content of cells with increasing growth rate; Herbert (1958) and Schaechter, Maaløe \& Kjeldgaard (1958) have observed that the RNA content of bacteria is directly related to growth rate. The true growth yield, $Y_{g}$, of $P$. chrysogenum for glucose, which was $0.08 \mathrm{I}$ g. dry wt $/ \mathrm{m}$-mole glucose and for oxygen $0.050 \mathrm{~g}$. dry wt $/ \mathrm{m}$-mole $\mathrm{O}_{2}$, did not vary with growth rate.

The fate of the maintenance glucose and oxygen can be seen by comparing the maintenance coefficients with the specific rates of formation of the products of carbon and energy metabolism extrapolated to zero growth rate (Fig. 3). Of the maintenance glucose-carbon $8 \%$ was recovered as penicillin, the remainder as carbon dioxide. Of the maintenance oxygen, $90 \%$ was equivalent to the carbon dioxide formed. The maintenance requirement for glucose and oxygen would thus appear to be primarily used as a source of energy. 


\section{Effect of decreasing glucose supply to the maintenance ration}

If extrapolation of Fig. 3 to zero growth rate describes the glucose metabolism of non-growing mould, it would be expected that a glucose supply rate of $0.12 \mathrm{~m}$-moles glucose/g. dry wt/hr would maintain the mycelium concentration constant, most of the glucose would be oxidized to carbon dioxide and penicillin would be produced at the same rate as in growing cultures. Non-growing cultures were obtained experimentally by stopping the flow of medium to steady-state chemostat cultures and supplying only glucose at the maintenance rate. Glucose supplied in this way was termed the 'main-

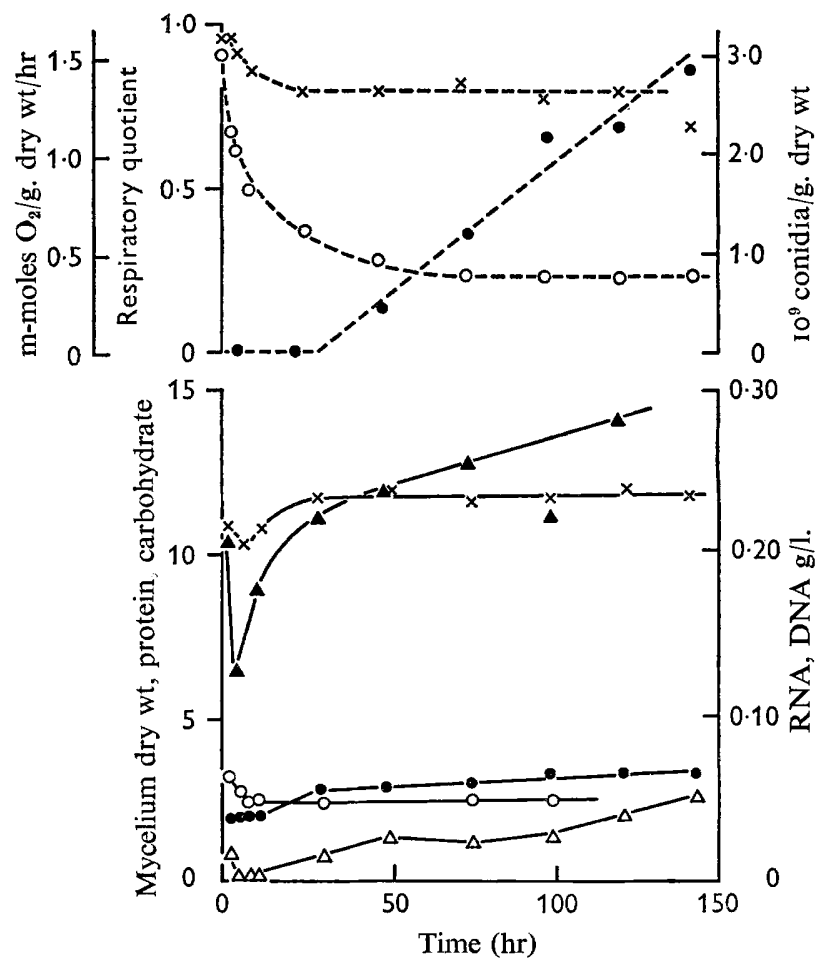

Fig. 4. Conidia production and changes in respiration and macromolecular composition of Penicillium chrysogenum wIS 54-1255 supplied the maintenance ration of glucose $(0.022 \mathrm{~g}$. glucose/g. dry wt organism/hr) after steady-state growth in glucose-limited chemostat culture at a specific growth rate of $0.05 \mathrm{I} \mathrm{hr}^{-1}$. Zero time points are the steady-state chemostat observations. Broken lines: $\times \times \times$, respiratory quotient $\left(\mathrm{CO}_{2} / \mathrm{O}_{2}\right) ; \mathrm{O}$, specific oxygen uptake rate; $\ominus$, conidia. Continuous lines: $\times \times \times$, mycelium dry weight; $O$, mycelium protein; $\bullet$, mycelium carbohydrate; $\triangle$, DNA; $\Delta$, RNA.

tenance ration'. All other substrates, including oxygen, were present in excess. The maintenance ration maintained constant the mycelial dry weight and, after a slight initial adjustment, the cellular protein and carbohydrate; but the nucleic acid composition was not maintained (Fig. 4). The data of Fig. 4 indicate that there was a considerable turnover of both RNA and DNA during the ageing of non-growing maintained cultures. When the glucose supply was decreased to the maintenance ration the respiration rate fell to a lower value than that predicted $\left(0 \cdot 74 \mathrm{~m}\right.$-moles $\mathrm{O}_{2} / \mathrm{g}$. dry 
$\mathrm{wt} / \mathrm{hr}$ ) for zero growth rate. The decrease in the respiration rate was accompanied by a change in the respiratory quotient $\left(\mathrm{CO}_{2} / \mathrm{O}_{2}\right)$ which decreased from 0.97 to 0.72 (Table I). Only half the glucose carbon was then recovered as $\mathrm{CO}_{2}$ and acid began to accumulate in the medium at the rate of $0.1-0.2 \mathrm{~m}$-moles $\mathrm{H}^{+} / \mathrm{g}$. dry wt/hr. Thus there appeared to be a qualitative change in the glucose metabolism in the maintained state. The time taken for this change in glucose metabolism to occur, as measured by the onset of acid production, was proportional to the previous growth rate of the mould. The time of the change was Io $\mathrm{hr}$ after growth stopped when the previous growth rate was $0.023 \mathrm{hr}^{-1}$ and $49 \mathrm{hr}$ when the previous growth rate was $0.053 \mathrm{hr}^{-1}$. The penicillin synthetic activity of the mould decreased to zero after growth was stopped at a rate related inversely to the previous growth rate (Pirt \& Righelato, 1967).

Glucose supplied in excess of the maintenance ration inhibited the change in glucose metabolism and at a supply rate $2.5 \times$ maintenance ration, the metabolic quotients for oxygen, carbon dioxide, penicillin and cell material remained constant. At this glucose supply rate steady-state growth homologous with that of the chemostat culture was observed.

Conidiation, like the time of onset of acid production and the decay in penicillin synthetic activity, was related to the previous growth rate of the mould. In a culture supplied the glucose maintenance ration after growth at a specific growth rate of $0.023 \mathrm{hr}^{-1}, 2.6 \times 10^{9}$ conidia/g. dry wt were counted $45 \mathrm{hr}$ after cessation of growth. When the previous growth rate was $0.053 \mathrm{hr}^{-1}$, only $\mathrm{I} \cdot 0 \times 10^{9}$ conidia/g. dry wt were present at $45 \mathrm{hr}$. Once the differentiation described above, involving the glucose metabolism, hyphal vacuolation, conidiation and cessation of penicillin production was complete, the culture appeared not to change further. In one culture grown initially at a specific growth rate of $0.023 \mathrm{hr}^{-1}$ (residence time $=43 \mathrm{hr}$ ) the adaptation to the non-growing state was complete within $50 \mathrm{hr}$ and the only difference observed $\mathrm{I} 70 \mathrm{hr}$ later was an increase in the number of conidia present. Another culture grown at $0.086 \mathrm{hr}^{-1}$ (residence time $=\mathrm{II} \cdot 6 \mathrm{hr}$ ) took about $150 \mathrm{hr}$ to complete the ageing process. The total age of the organism at the completion of the ageing process in the former culture was about $90 \mathrm{hr}$ and in the latter about $\mathrm{I} 60 \mathrm{hr}$. Thus the time taken for the mould to complete the differentiation was not determined by its overall age.

The influence of the glucose metabolic rate on the rate of formation of conidia is shown in Table $\mathrm{I}$. There was an optimum glucose metabolic rate for conidia production $(0.21 \mathrm{~m}$-moles glucose/g. dry wt $/ \mathrm{hr})$, that is, about $\mathrm{r} \cdot 7 \times$ maintenance ration. In the absence of any glucose feed autolysis occurred without conidiation. The conidia were not observed to germinate in the culture but were subsequently found to be viable.

It is difficult to assess the viability of the hyphae of a filamentous organism such as Penicillium chrysogenum. Since large amounts of empty hyphal walls did not accumulate in the cultures supplied glucose at the maintenance ration and above, and the protein content of the mycelium remained constant, it is thought that most of the hyphae were actively metabolizing.

\section{Light microscopy}

Chemostat cultures. The cultures were composed of filamentous hyphae together with a few mycelial pellets; the diameter of the pellets never exceeded I $\mathrm{mm}$. and the mean length of the hyphal filaments at a specific growth rate of $0.053 \mathrm{hr}^{-1}$ was $189 \pm 80$ $\mu$. The occurrence of the pellet growth form increased with growth rate, though with 
Penicillium chrysogenum WIS 54-I255 it always formed only a small proportion of the total mycelial mass. At the maximum growth rate $\left(0.09 \mathrm{hr}^{-1}\right)$ there were about three times as many pellets as at $0.075 \mathrm{hr}^{-1}$ and ten times as many as at $0.053 \mathrm{hr}^{-1}$. Pellets were not observed at growth rates below $0.04 \mathrm{hr}^{-1}$. Associated with the pellet growth habit were aberrant mycelial forms, large swollen cells up to three or four times the diameter of the normal hyphae and very closely branched hyphal systems (Pl. I, fig. I). The closely branched systems may be early stages in the growth of pellets. Pirt \& Callow (1959) observed similar swollen cells, close branching and stromatic pellets

Table $\mathrm{I}$. The relationship between glucose supply rate, specific growth rate, oxidation of glucose and conidiation by Penicillium chrysogenum wIS 54-1255

\begin{tabular}{|c|c|c|c|c|}
\hline $\begin{array}{c}\text { Growth rate } \\
\mathrm{hr}^{-1}\end{array}$ & $\begin{array}{c}\text { Glucose } \\
\text { supply rate } \\
\text { g. glucose/g. } \\
\text { dry wt/hr }\end{array}$ & $\begin{array}{l}\text { \% glucose } \mathrm{C} \text { utilized } \\
\text { (excluding glucose } \\
\text { recovered as cell } \\
\text { and penicillin } \mathrm{C} \text { ) } \\
\text { recovered as } \mathrm{CO}_{2}\end{array}$ & $\begin{array}{l}\text { Respiratory } \\
\text { quotient }\end{array}$ & $\begin{array}{l}10^{9} \text { conidia/g. } \\
\text { dry wt }\end{array}$ \\
\hline $0^{*}$ & 0.022 & 47 & 0.72 & $2 \cdot 9$ \\
\hline $0.009^{*}$ & 0.038 & 71 & 0.90 & 6.5 \\
\hline $0.014 * \uparrow$ & 0.056 & 72 & 0.94 & 0.6 \\
\hline $0.023 \ddagger$ & 0.068 & 82 & 0.95 & 0 \\
\hline $0.051 \ddagger$ & $0 \cdot 133$ & 72 & 0.97 & 0 \\
\hline $0.075 \ddagger$ & 0.189 & 63 & 0.98 & 0 \\
\hline
\end{tabular}

* Readings taken $90 \mathrm{hr}$ after cessation of chemostat growth phase at a specific growth rate of $0.051 \pm 0.002 \mathrm{hr}^{-1}$.

$\dagger$ Steady state, exponential growth.

\$lucose-limited chemostat culture.

in glucose-limited chemostat cultures of $P$. chrysogenum WIS 54-I255 growing at $0.05 \mathrm{hr}^{-1}$. They found that pellets were the predominant growth form at $\mathrm{pH}$ values above those optimal for the production of long thin sparsely-branched hyphae. Bent \& Morton (1963), also with $P$. chrysogenum, observed similar aberrant hyphae to those described above when the $\mathrm{pH}$ value was very near to the minimum at which mycelial growth would occur $(\mathrm{pH}=2 \cdot 15-2 \cdot 35)$.

The apical $5^{-15} \mu$ of normal filaments contained non-vacuolated protoplasm but vacuoles of various sizes were found further from the tips (Pl. I, fig. I, 2). A similar morphology was observed when the fungus was grown on solid media. A few hyphae in the chemostat cultures were more vacuolated than the rest; they may have represented filaments which had been in the culture longest.

Non-growing organism and conidiation. The most marked morphological change in the culture after its growth had been stopped and then supplied the glucose maintenance ration, was an increase in hyphal vacuolation; even the apical hyphal 'cells' were usually vacuolated (P1. I, fig. 4). The vacuolation of hyphal tips was related to the growth rate of the mould. In the non-growing cultures supplied glucose at the maintenance ration most tips were vacuolated; at growth rates of 0.014 and above most were non-vacuolated (Pl. I, fig. 2; Pl. 2, fig. 8). Vacuole formation may play an important part in hyphal growth. Translocation of cell material from the vacuolating regions to the growing tips may allow higher rates of hyphal extension than could obtain solely by synthesis at the hyphal tips.

Another major morohological change in the maintained culture was the appearance 
of phialides and conidia. Throughout the period in which glucose was supplied at the maintenance ration there was an increase in the number of these structures present in the culture (Fig. 4). The phialides were usually formed singly at the tips of hyphae (Pl. I, fig. 3) but pairs of phialides were also common (Pl. I, fig. 5) and occasionally groups of three were observed. Penicillia consisting of more than one phialide were more common and conidiation was more rapid when glucose was supplied at $\mathrm{I} \cdot 7 \times$ maintenance ration. The species Penicillium chrysogenum forms a typical asymmetrical penicillus when cultured on solid media (Pl. I, fig. 6, 7). The free spores (PI. I, fig. 3) in the culture were spherical in shape and had a mean diameter of $2.0 \pm 0.5 \mu$. They were non-vacuolated and appeared to be dormant, since none were observed in the process of germination. Never more than one spore was attached to a phialide; the formation of spore chains, which is a characteristic feature of asexual reproduction under aerial conditions (Pl. I, fig. 6, 7) was presumably prevented by the vigorous agitation of the culture. As the non-growing mould aged, the branched hyphal systems broke into smaller units and the viscosity of the culture decreased. In all cultures a few empty hyphae and a little protoplasmic debris were observed, due presumably to the shearing action of the impeller.

\section{Electron microscopy of growing and non-growing mould}

In some sections the hyphal walls appeared to be composed of two faintly divided layers of approximately equal thickness; in other sections, however, the walls appeared to consist of a single layer. An ill-defined aggregation of electron-dense material was present around the outside of some hyphae. Similar layers have been observed around the hyphae of Neurospora crassa (Shatkin \& Tatum, 1959) and Aspergillus niger (Tanaka \& Yanagita, 1963).

There was little difference in the thickness of the walls of hyphae cultured at the growth rates examined (Table 2). The presence of small cytoplasmic invaginations in the inner layer of the wall appeared to be a characteristic feature of the hyphae (Pl. 2, fig. 9). Tangential sections of the walls revealed that this inner layer had a reticulate appearance which indicates that the invaginations take the form of papillae rather than grooves (Pl. 3, fig. II). The only detectable morphological difference between the walls of the maintained hyphae and of the growing hyphae was the somewhat greater prominence of the cytoplasmic invaginations of the inner layer in the maintained hyphae.

Table 2. Penicillium chrysogenum WIS 54-I255: thickness of the walls of hyphae grown under various conditions

\begin{tabular}{|c|c|c|c|c|}
\hline \multirow[b]{2}{*}{ Cultural conditions } & \multirow[b]{2}{*}{ Growth rate } & \multirow[b]{2}{*}{$\begin{array}{l}\text { Doubling } \\
\text { time (hr) }\end{array}$} & \multicolumn{2}{|c|}{ Wall thickness $(\mathrm{m} \mu)$} \\
\hline & & & $\begin{array}{c}\text { Extreme values } \\
\text { observed }\end{array}$ & $\begin{array}{l}\text { Mean } \\
\text { value }\end{array}$ \\
\hline ostat culture & $0.075 \mathrm{hr}^{-1}$ & 13 & $86-240$ & 144 \\
\hline lostat culture & $0.053 \mathrm{hr}^{-1}$ & 19 & $120-280$ & 159 \\
\hline re maintained for 2 days & 0 & - & I 28-I94 & I 54 \\
\hline re maintained for 4 days & 0 & - & $62-156$ & 124 \\
\hline
\end{tabular}

Several septa of hyphae from growing and non-growing cultures were sectioned through the region of their pores. Each septum was perforated by a more or less centrally placed pore which was plugged with electron-dense material. In most cases 
membrane-bound electron-dense structures were present in the cytoplasm on either side of the pore (Pl. 3, fig. I2). These structures seem to be identical to the so-called Woronin bodies which Reichle \& Alexander (I965) found associated with the septal pores of Fusarium spores and hyphae. Reichle \& Alexander suggested that the function of these structures is to plug the pores when hyphae become damaged. If the septal pores were to become occluded soon after their formation it would most certainly decrease the amount of protoplasm lost as a consequence of shear. The manner in which the septal pores are plugged and the conditions which influence the process have not yet been investigated. Whether or not mechanical agitation enhances the process of plugging remains to be determined.

The nuclei present in the hyphae were of the usual eucaryotic type and the hyphal 'cells' were multinucleate. The mitochondria possessed few cristae and a relatively sparse endoplasmic reticulum ramified throughout the hyphae. These features appear to be typical of the cellular organization of fungal hyphae. Although a large number of sections was examined, no structures resembling dictyosomes or lomasomes were observed.

Organisms supplied glucose at the maintenance ration showed none of the morphological signs of mitochondrial and nuclear degeneration observed by Bracker (I966) in developing sporangia of Gilbertella persicaria. The structural features of those organelles of Penicillium chrysogenum appearing in electron micrographs were maintained by the maintenance ration of glucose (Pl. 3, fig. I I) However, the extensive vacuolation observed in the non-growing cultures might mean that the total number of these organelles had decreased.

Vacuoles with flocculent contents were present in the cytoplasm of some sections of growing organisms but not in others. Each vacuole was bounded by a unit membrane, the tonoplast, which had the same appearance as the protoplasmic membrane. There was a variation in the size of the vacuoles and in some cases there was more than one vacuole present per 'cell' (Pl. 2, fig. IO). In some sections diffuse, electron transparent areas were present in the cytoplasm adjacent to the hyphal walls (Pl. 3, fig. I2). These regions were never bounded by a membrane, which indicates that they were probably not associated with vacuole formation.

A considerably greater proportion of the hyphae in samples taken from the maintained culture contained vacuoles. In some cases a single vacuole occupied almost the entire area of the hyphal lumen, leaving only a narrow 200-300 $\AA$ rim of cytoplasm between the tonoplast and the protoplasmic membrane (Pl. 3, fig. 13). Examination of a large number of sections failed to reveal the presence in the cytoplasm of glycogen, which usually appears as small rosettes of electron-dense particles (Revel, Napolitano \& Fawcett, I960). The absence of a carbohydrate reserve is to be expected when growth is carbohydrate-limited. A few small lipid inclusions were detected in sections of both growing and maintained hyphae, and the presence of small amounts of this reserve was also confirmed by staining fresh material with Sudan III.

\section{DISCUSSION}

The specific utilization rates (utilization rate/g. mycelium dry wt) of glucose and oxygen during glucose-limited growth of Penicillium chrysogenum WIS 54-I 255 were related linearly to specific growth rate. They have been resolved into growth rate dependent and growth rate independent components, the latter being the substrate 
requirement at zero growth rate or the substrate requirement for maintenance energy. The catabolism of glucose in the growing cultures differed from that of the nongrowing mould, a greater proportion of the catabolized glucose was converted to carbon dioxide in growing cultures. From $0.014 \mathrm{hr}^{-1}$ to nearly the maximum specific growth rate $\left(0.09 \mathrm{hr}^{-1}\right)$ steady states with homologous carbon metabolism were obtained.

Over nearly the whole of its growth rate range the mould was essentially filamentous and its morphology varied little. However, growth rate did determine the degree of vacuolation and the proportion of swollen cells and pellets in the cultures. The most important conclusion to be drawn from the electron microscope studies is that the observed ultrastructure of the cytoplasm (excluding vacuoles) did not change with the specific growth rate even down to the zero growth rate of the maintained cultures. The ribosome content of the cell would be expected to vary with the growth rate; however, ribosomes were not shown up by the permanganate fixation.

The maintenance ration of glucose was necessary to maintain mycelial dry weight, protein content and ultrastructure of the non-growing mould, but the maintenance ration did not prevent cell reorganization followed by conidiation. Glucose was essential to permit conidiation and maximum conidiation occurred at a growth rate between zero (i.e. supplied the maintenance ration of glucose) and $0.014 \mathrm{hr}^{-1}$ (doubling time $=50 \mathrm{hr}$ ), the critical growth rate above which steady state vegetative growth occurred.

The reorganization of cell material necessary to bring about the transition from the vegetative to the conidiating state probably depends to a large extent on turnover of macromolecules. The rapid changes of cellular RNA and DNA concentrations which occurred soon after stopping the growth of chemostat cultures and supplying the glucose maintenance ration probably indicated breakdown of macromolecules and reorganization, perhaps elsewhere in the hyphae, e.g. the phialides. The glucose maintenance ration supplies energy for this process and in its absence autolysis occurs without conidiation.

Conidiation of Penicillium griseofulvum can be induced by transfer to nitrogen-free media with high concentrations of calcium and sugar (Morton, I96I). Morton reported that $P$. chrysogenum (ARL no. 167 ) remained obstinately vegetative in submerged conditions after transfer to nitrogen-free media. However, the strain wis 54-I 255 used in the present study sporulated in glucose-limited cultures and in shaken flasks in which nitrogen was the first substrate to become exhausted. In both nitrogenexhausted media and in cultures supplied glucose at or near the maintenance ration, with ammonia and all other substrates in excess, growth was restricted to a rate at or near zero.

Our results reinforce the generally held opinion that conidiation occurs in response to conditions which severely restrict vegetative growth. The restrictions may be imposed by the exhaustion of the nitrogen sources and perhaps some other substrates whilst the energy source is still present, or by the limited availability of the energy source, other essential substrates being in excess. The biochemistry of sporulation in fungi is little understood. There is some evidence from other workers (Hawker \& Hepden, 1962; Bu'Lock, I965; Turian, 1966) and from the non-growing mould in the present study that sporulation is preceded by a qualitative change in the energy metabolism of the organism, but in no case have the biochemical changes been clearly 
characterized. Our observations show that although conidiation in non-growing cultures was accompanied by a change in glucose catabolism, maximum conidiation occurred when the catabolism was like that of growing cultures.

The mechanism relating the rate of conidiation in a non-growing mould to its previous growth rate is not understood. The age of the mycelium does not appear to control the ageing processes. Unidentified metabolites have been postulated as sporulation inducers (Hadley \& Harrold, 1958) and as vacuolation inducers (Park \& Robinson, 1964). It is possible that such substances are produced by Penicillium chrysogenum in the cultures described here. Another possibility is that the time taken to break down the RNA present in the cells at the cessation of growth, and its resynthesis as a species appropriate to the new conditions, is a function of the amount of RNA in the cells, which probably increases with increasing growth rate. Whatever the cellular mechanisms involved, it is clear that the differentiation of $P$. chrysogenum during glucose-limited growth is controlled by its history and the rate of supply of glucose. Above a critical glucose supply rate giving a specific growth rate of $0.014 \mathrm{hr}^{-1}$ only vegetative mould was produced. Below that value, conidiation, penicillin production and the oxidative metabolism were controlled by the rate at which glucose was supplied.

\section{REFERENCES}

BARTNICKI-GARCIA, S. \& NickeRson, W. J. (1962). Isolation, composition and studies of cell walls of filamentous and yeast-like forms of Mucor rouxii. Biochim. biophys. Acta 58, I02.

Bent, W. J. \& Morton, A. G. (1963). Formation and nature of swollen hyphae in Penicillium and related species. Trans. Br. mycol. Soc. 46, 401 .

BraCKer, C. E. (1966). Ultrastructural concepts of sporangiospore formation in Gilbertella persicaria. The Fungus Spore. London: Butterworth.

Bu'Lock, J. D. (1965). In Biogenesis of Antibiotic Substances. Ed. by Z. Vanek \& A. Hostalek. London: Academic Press, p. 6I.

Burton, K. (1956). A study of the conditions and mechanism of the diphenylamine reaction for the colorimetric estimation of deoxyribose nucleic acid. Biochem. J.62, 315.

Conway, E. J. (1957). Microdiffusion Analysis and Volumetric Error, 4 th ed. New York: Lockwood.

Hadley, G. \& Harrold, C. E. (I958). The sporulation of Penicillium notatum, Westling, in submerged liquid culture. II. J. exp. Bot. 9, 4I8.

HAWKER, L. E. (1939). The influence of various sources of carbon on the formation of perithecia by Melanospora destruens Shear in the presence of accessory growth factors. Ann. Bot., Lond. N.S. 3, 455 .

Hawker, L. E. \& Hepden, P. M. (1962). Sporulation of Rhizopus sexualis and some other fungi following a period of intense respiration. Ann. Bot., Lond. N.S. 26, 619.

Herbert, D. (1958). Some principles of continuous culture. In Recent Progress in Microbiology 8th. int. Congr. Microbiol, p. 381. Oxford: Blackwell Scientific Publications.

JaRvis, F. G. \& Johnson, M. J. (I947). The role of the constituents of synthetic media for penicillin production. J. Am. chem. Soc. 69, 3010.

Morton, A. G. (196r). The induction of sporulation in mould fungi. Proc. R. Soc. B r53, 548.

MoYer, A. J. \& Coghill, R. D. (I946). Penicillin VIII. Production of penicillin in surface culture. J. Bact. 5I, 57.

Park, D. \& Robinson, P. M. (1964). Isolation and bioassay of a fungal morphogen. Nature, Lond. $203,988$.

PIRT, S. J. (1965). The maintenance energy of bacteria in growing cultures. Proc. R. Soc. B I63, 24.

PIRT, S. J. (1966). A theory of the mode of growth of fungi in the form of pellets in submerged culture. Proc, $R$. Soc. B I66, 369.

PIRT, S. J. \& Callow, D. S. (I959). Continuous-flow culture of the filamentous mould Penicillium chrysogenum and the control of its morphology. Nature, Lond. 184, 307. 
PIRT, S. J. \& Callow, D. S. (1960). Studies of the growth of Penicillium chrysogenum in continuousflow culture with reference to penicillin production. J. appl. Bact. 23, 87 .

PirT, S. J. \& Righelato, R. C. (1967). The effect of growth rate on the synthesis of penicillin by Penicillium chrysogenum in batch and chemostat cultures. Appl. Microbiol. 15, 1284 .

Reichle, R. E. \& AleXANDer, J. V. (1965). Multiperforate septations, Woronin bodies and septal plugs in Fusarium. J. cell Biol. 24, 489.

Revel, J. P., Napolitano, L. \& FawCEtt, D. W. (I960). Identification of glycogen in electron micrographs of thin tissue sections. J. biophys. biochem. Cytol. 8, 575 .

Righelato, R. C. \& PIRT, S. J. (1967). Improved control of organism concentration in continuous cultures of filamentous micro-organisms. J. appl. Bact. 30, 246.

Schaechter, M., MaAløe, O. \& KJeldgaARd, N. O. (I958). Dependency on medium and temperature of cell size and chemical composition during balanced growth of Salmonella typhi-murium. J. gen. Microbiol. 19, 592.

Shatkin, A. J. \& TATUM, E. L. (1959). Electron microscopy of Neurospora crassa mycelia. J. biophys. biochem. Cytol. 6, 423 .

SмiтH, J. H. (1924). On the early growth rate of the individual fungus hypha. New Phytol. $29,65$.

STICKLAND, L. H. (I95I). The determination of small quantities of bacteria by means of the Biuret reaction. J. gen. Microbiol. 5, 698.

TANAKA, K. \& Yanagita, T. (1963). Electron microscopy of ultrathin sections of Aspergillus niger. I. Fine structure of hyphal cells. J. gen. appl. Microbiol. 9, IOI.

TEMPEST, D. W. \& HerberT, D. (I965). Effect of dilution rate and growth-limiting substrate on the metabolic activity of Torula utilis. J. gen. Microbiol. 4I, I43.

Terroine, E. F. \& Wurmser, R. (I922). L'énergie de croissance I. Le développement de l'Aspergillus niger. Bull. Soc. Chim. Biol. 4, 519.

TREVElyan, W. E. \& HARRISON, J. S. (I952). Fractionation and microdetermination of cell carbohydrates. Biochem. J. 50, 298.

Turian, G. (1966). Morphogenesis in Ascomycetes. In The Fungi, vol. II. Ed. by G. C. Ainsworth and A. S. Sussman. London: Academic Press.

UMBreIt, W. W., BURris, R. H. \& StAUfFer, J. H. (1947). Manometric Techniques andRelated Methods for the Study of Metabolism. Minneapolis: Burgess Publishing Co.

Whiffen, A. J. \& SAvage, G. M. (1947). The relation of natural variation in Penicillium notatum to the yield of penicillin in surface culture. J. Bact. 53, $23 \mathrm{I}$.

\section{EXPLANATION OF PLATES}

\section{Abbreviations used}

$\mathrm{c}=$ septum $; \mathrm{cw}=$ hyphal wall $; \mathrm{ct}=$ cytoplasm $; \mathrm{e}=$ hyphae empty of contents $; \mathrm{er}=$ endoplasmic reticulum; et = electron transparent area of cytoplasm; $\mathrm{i}=$ wall invagination; $\mathrm{m}=$ mitochondrion; $\mathrm{n}=$ nucleus $; \mathrm{nv}=$ non-vacuolated hyphal tip; $\mathrm{p}=$ phialide $; \mathrm{pm}=$ protoplasmic membrane; $\mathrm{s}=$ spore; $\mathrm{sp}=$ septal plug; $\mathrm{t}=$ tonoplast $; \mathrm{t}=$ tangential section of hyphal wall; $\mathrm{v}=$ vacuole; $\mathrm{vt}=$ vacuolated hyphal tip; $\mathrm{w}=$ Woronin body.

\section{Plate I}

Light micrographs of Penicillium chrysogenum wIS 54-I 255

Fig. I. Mould taken from a glucose-limited chemostat culture at a specific growth rate of $0.053 \mathrm{hr}^{-1}$. Showing separately branched filaments with few vacuoles and some swollen abberrant cells.

Fig. 2. Mould taken from a glucose-limited culture growing at a specific rate of $0.053 \mathrm{hr}^{-1}$. Showing the distribution of vacuoles in a hypha.

Figs. 3-5. Mould from a non-growing culture supplied only the maintenance ration of glucose for $45 \mathrm{hr}$. The hyphae are considerably more vacuolated than those in figs. I-2. The filaments have a typically banded appearance after they have been stained with trypan blue. In each 'cell' there is a large central vacuole. Some hyphae have formed phialides at their tips and free spores may be detected in the culture.

Figs. 6-7. Sporing heads of $P$. chrysogenum taken from a culture grown on $0.1 \%$ Difco malt extract, $2 \%$ agar. 


\section{Plate 2}

Light and electron micrographs of Penicillium chrysogenum wis 54-1255

Fig. 8. Light micrograph of mould taken from a glucose-limited culture growing at a specific rate of $0.014 \mathrm{hr}^{-1}$. Showing hyphae less vacuolated than those of the non-growing mould.

Figs. 9-IO. Electron micrographs of hyphae from a glucose-limited chemostat culture growing at a specific rate of $0.053 \mathrm{hr}^{-1}$. Showing a section through a plugged septum, mitochondria, nuclei, vacuoles and endoplasmic reticulum.

\section{Plate 3}

Electron micrographs of Penicillium chrysogenum wis 54-1255

Figs. I I-I3. Electron micrographs of hyphae from a non-growing culture supplied only the maintenance ration of glucose for $96 \mathrm{hr}$. Showing sections through a plugged septum with the associated Woronin bodies (fig. 12) and through a highly vacuolated part of a hypha (fig. 13). 
Journal of General Microbiology, Vol. 50, No. 3

Plate I
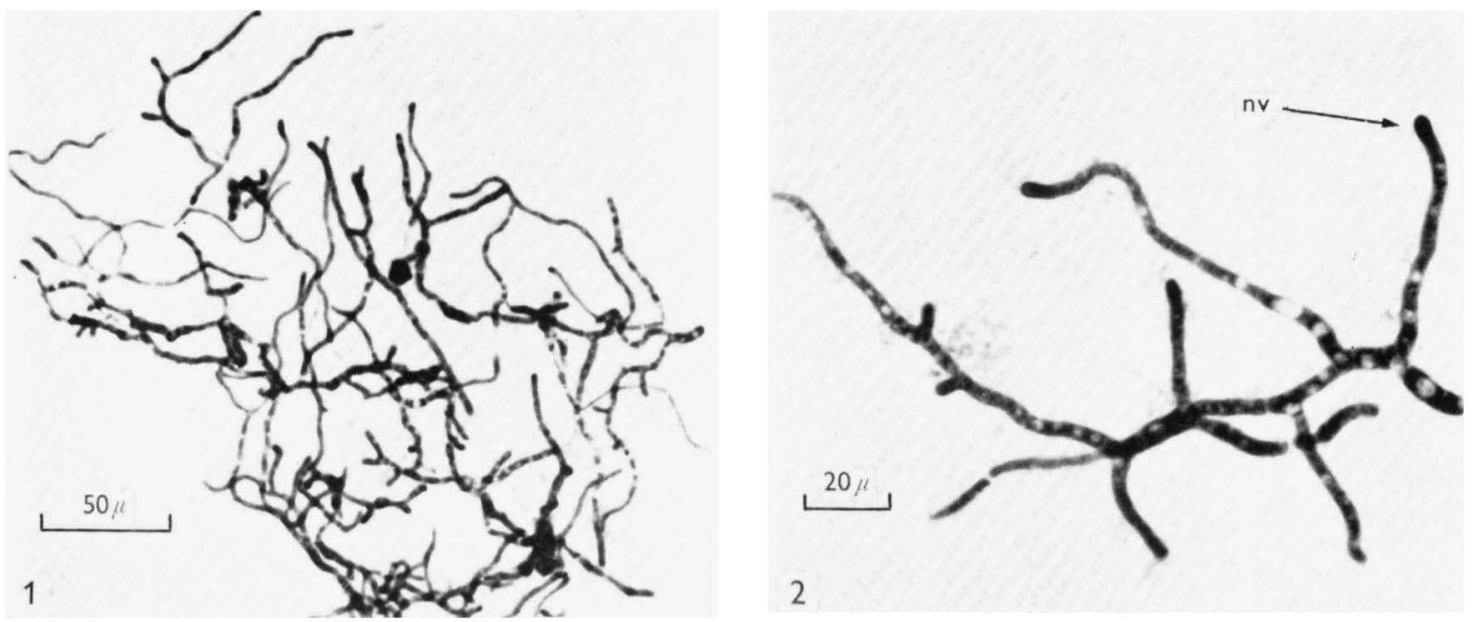

2
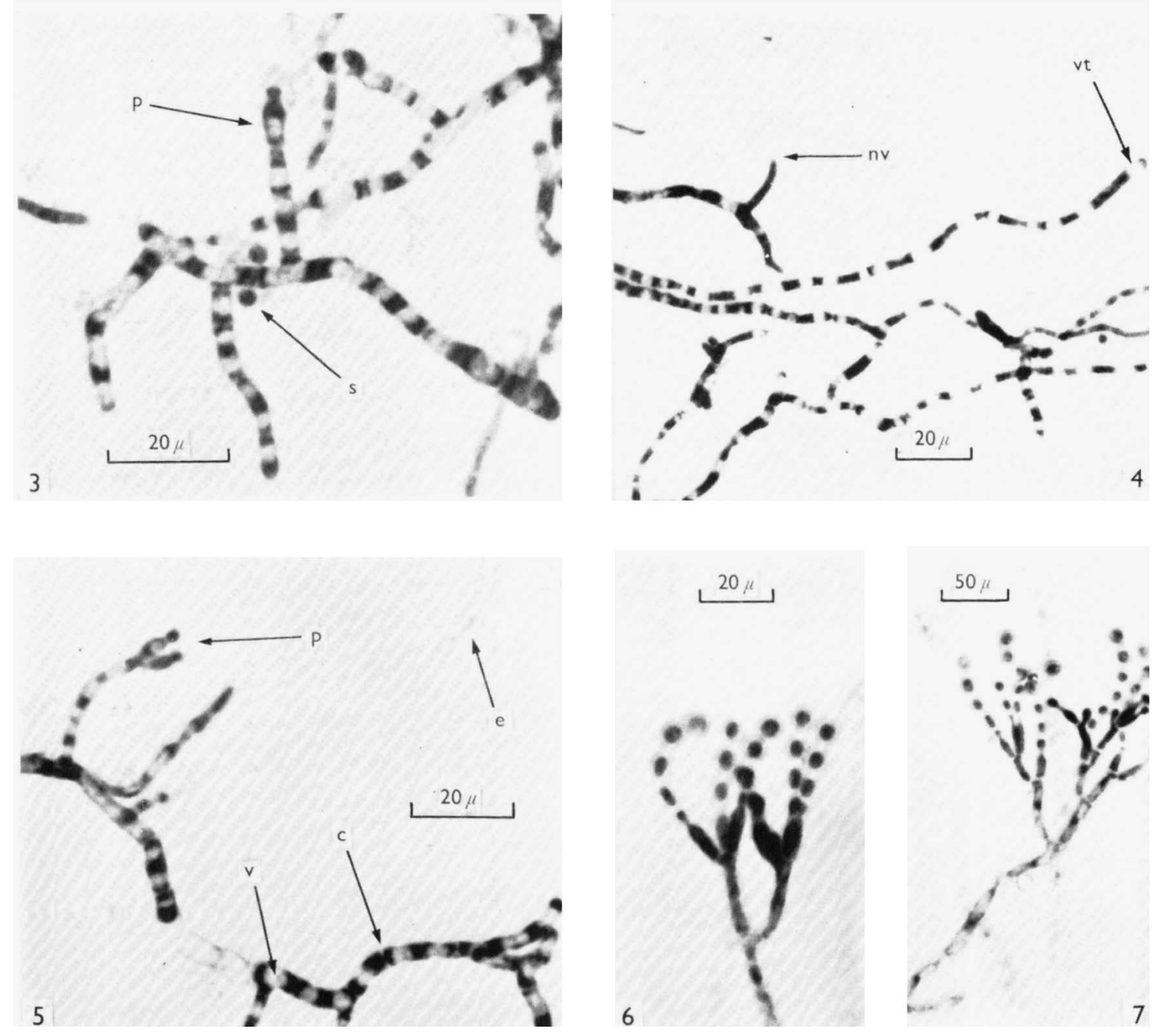

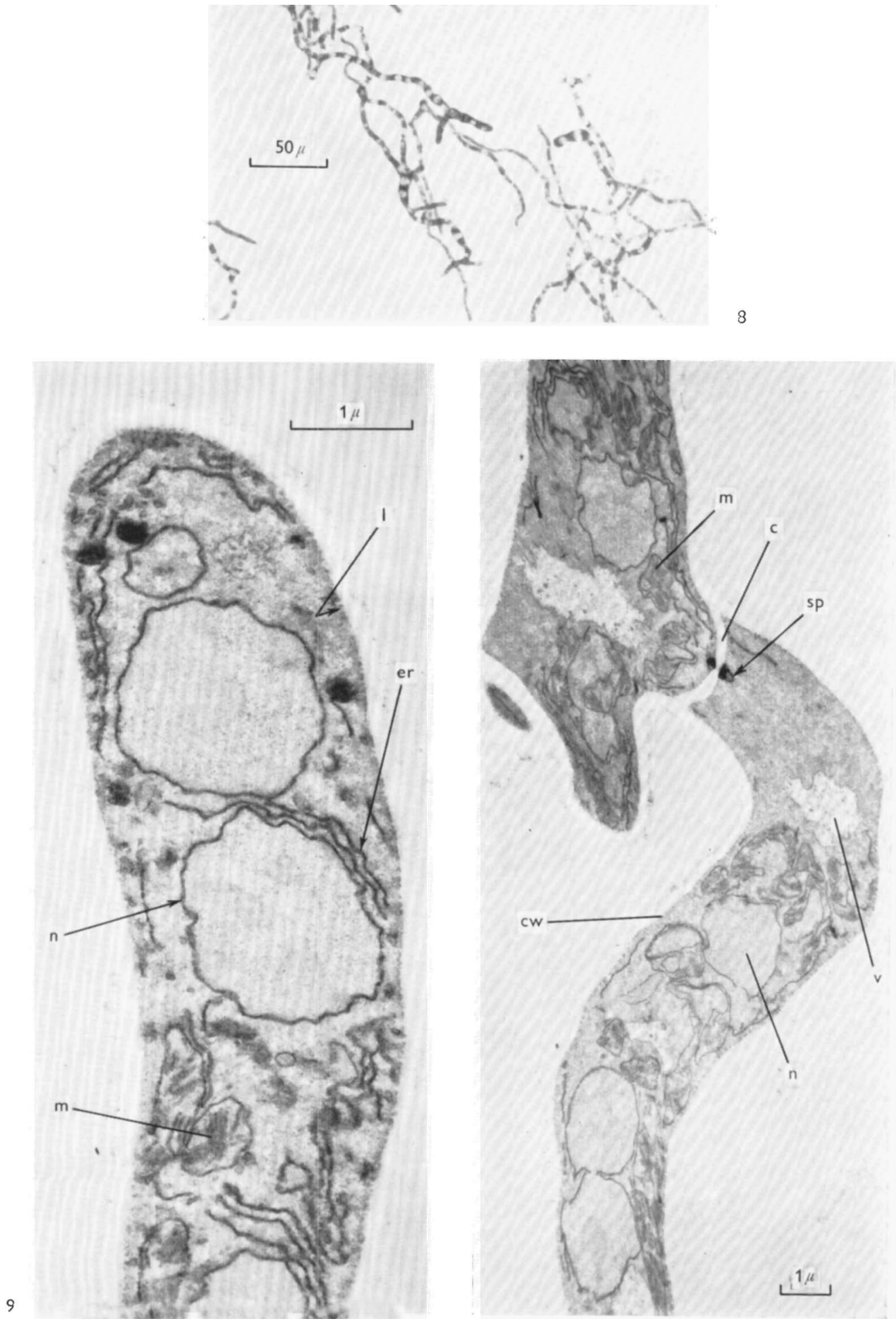

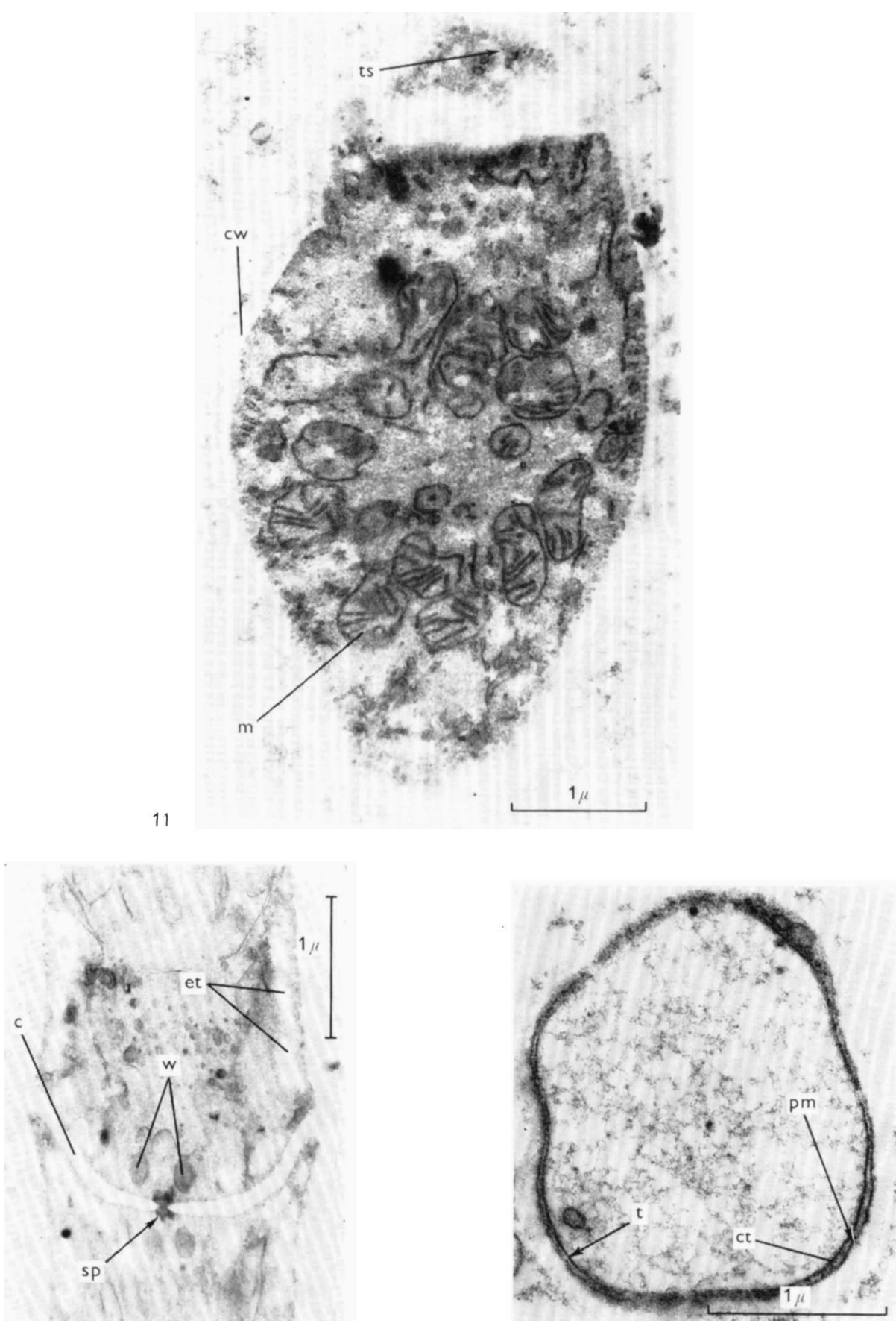